\title{
Updated cloud physics in a regional atmospheric climate model improves the modelled surface energy balance of Antarctica
}

\author{
J. M. van Wessem ${ }^{1}$, C. H. Reijmer ${ }^{1}$, J. T. M. Lenaerts ${ }^{1}$, W. J. van de Berg ${ }^{1}$, M. R. van den Broeke ${ }^{1}$, and \\ E. van Meijgaard ${ }^{2}$ \\ ${ }^{1}$ Institute for Marine and Atmospheric Research Utrecht, Utrecht University, Utrecht, the Netherlands \\ ${ }^{2}$ Royal Netherlands Meteorological Institute, De Bilt, the Netherlands
}

Correspondence to: J. M. van Wessem (j.m.vanwessem@uu.nl)

Received: 21 May 2013 - Published in The Cryosphere Discuss.: 1 July 2013

Revised: 2 December 2013 - Accepted: 3 December 2013 - Published: 22 January 2014

\begin{abstract}
In this study the effects of changes in the physics package of the regional atmospheric climate model RACMO2 on the modelled surface energy balance, nearsurface temperature and wind speed of Antarctica are presented. The physics package update primarily consists of an improved turbulent and radiative flux scheme and a revised cloud scheme that includes a parameterisation for ice cloud super-saturation. The ice cloud super-saturation has led to more moisture being transported onto the continent, resulting in more and optically thicker clouds and more downward long-wave radiation. Overall, the updated model better represents the surface energy balance, based on a comparison with $>750$ months of data from nine automatic weather stations located in East Antarctica. Especially the representation of the turbulent sensible heat flux and net long-wave radiative flux has improved with a decrease in biases of up to $40 \%$. As a result, modelled surface temperatures have increased and the bias, when compared to $10 \mathrm{~m}$ snow temperatures from 64 ice-core observations, has decreased from $-2.3 \mathrm{~K}$ to $-1.3 \mathrm{~K}$. The weaker surface temperature inversion consequently improves the representation of the sensible heat flux, whereas wind speed biases remain unchanged. However, significant model biases remain, partly because RACMO2 at a resolution of $27 \mathrm{~km}$ is unable to resolve steep topography.
\end{abstract}

\section{Introduction}

Understanding the climate of the polar regions and changes therein requires a thorough understanding of the surface energy balance (SEB), which describes the exchange of heat and moisture at the earth's surface. Regional atmospheric climate models (RCMs) are important tools to improve our understanding of polar SEB. They provide a physically consistent representation of the climate in areas with a low spatial and temporal coverage of observations. RCMs are also capable of resolving detailed features that are not captured by global circulation models. Specifically, RCMs have been successfully applied to remote areas such as Antarctica (e.g. Van Lipzig et al., 2002) and Greenland (Fettweis, 2007; Ettema et al., 2010a) to assess the SEB and surface mass balance (SMB) of these ice sheets (e.g. Van Lipzig et al., 1999; Van de Berg et al., 2005; Lenaerts et al., 2012a). Moreover, RCM output can be used to enhance the interpretation of remote sensing data such as GRACE (Chen et al., 2006), InSAR (Rignot et al., 2008) and radar/laser altimetry (Ligtenberg et al., 2012).

The Regional Atmospheric Climate Model RACMO2, which has been adapted for specific use over the polar regions, has recently undergone a major update of its physics package. In the present study we examine whether this update from version RACMO2.1 to RACMO2.3 has improved the representation of the Antarctic near-surface climate, with its extreme temperatures and winds, and surface energy balance. Even though RACMO2.1 has proved to realistically simulate the Antarctic near-surface climate (Van de Berg et al., 2005; Lenaerts et al., 2012a), previous model evaluations showed that downward long-wave radiation is generally underestimated by the model (Van de Berg et al., 2007) resulting in a significant cold surface bias (Van den Broeke, 2008). To see whether this has improved in RACMO2.3, we will assess the changes for Antarctica in SEB, near-surface 
wind speed and surface temperature and compare these to available observations. The Antarctic SEB historically has been the focus of many studies, based both on observations (Schlatter, 1970; Carroll, 1982; Reijmer and Oerlemans, 2002) and modelling (Van de Berg et al., 2007), including evaluations of models like RACMO (Van Lipzig et al., 1999; Reijmer et al., 2005). Here we use new data collected at Antarctic automatic weather stations (AWSs) that have been specifically designed to close and quantify the SEB (Reijmer and Oerlemans, 2002).

Section 2 discusses the model, the changes in model formulation and the observational data used for evaluation. In Sect. 3 the effects of the model changes on clouds, the SEB and the near-surface temperature and wind are presented and a comparison is made to observational data (Sects. 3.3-3.5), followed by conclusions in Sect. 4.

\section{Data and methods}

\subsection{RACMO2 physics update}

RACMO2 combines the dynamical processes of the High Resolution Limited Area Model (HIRLAM) (Undén et al., 2002) with the physics package of the European Centre for Medium-range Weather Forecasts (ECMWF) Integrated Forecast System (IFS). RACMO2 has been specifically adapted for use over the large ice sheets of Greenland and Antarctica (e.g. Reijmer et al., 2005). It is interactively coupled to a multilayer snow model that calculates melt, percolation, refreezing and runoff of meltwater (Ettema et al., 2010b; Greuell and Konzelmann, 1994). Surface albedo is based on a prognostic scheme for snow grain size (Kuipers Munneke et al., 2011) and a drifting snow routine simulates the interactions of drifting snow with the surface and the lower atmosphere (Lenaerts et al., 2012a). A horizontal resolution of $\sim 27 \mathrm{~km}$ and a vertical resolution of 40 levels is used. The model is forced by ERA-Interim re-analysis data (January 1979-December 2011, Dee et al., 2011) at the ocean and lateral boundaries, while the domain interior is allowed to evolve freely.

Here we analyse changes in the modelled Antarctic nearsurface climate after the ECMWF IFS physics package cycle CY23r4 in RACMO2.1 (White, 2001) has been updated to cycle CY33r1 in RACMO2.3 (ECWMF-IFS, 2008). The updates that have the most impact on Antarctic applications are the changes in the cloud scheme, the cloud microphysics and the radiation and turbulence schemes. All changes will be described below and are discussed in more detail in relation with the results in Sects. 3.3-3.5.

An important change in the cloud scheme is the inclusion of a parameterization for ice super-saturation as described by Tompkins and Gierens (2007). As a result, the specific humidity of cold air parcels (at temperatures where the difference between liquid water and ice saturation pres- sure is large) has to reach a higher value in order for condensation to occur. This leads to an improved representation of clouds and moisture concentrations in the (upper) troposphere (Tompkins and Gierens, 2007). Aircraft observations with the Microwave Limb Sounder (MLS) have shown that super-saturation frequently occurs over the steep coastal regions of Antarctica (Spichtinger et al., 2003). Simulations with the ECMWF IFS have already shown that the new parameterisation leads to a better global distribution of supersaturated atmospheres, albeit with a slight underestimation for Antarctica (Tompkins and Gierens, 2007).

Another change in the physics is the introduction of the McRad radiation scheme (Morcrette et al., 2008). It describes shortwave and long-wave radiation transfer through clouds, based on the Monte Carlo Independent Column Approximation (McICA, Barker et al., 2008), and a revision of cloud optical properties making the parameterisations that use these properties more accurate. This improves the interaction of multi-layer cloud cover with shortwave and longwave radiation, but is believed to be of minor importance for Antarctica, considering the low occurrence frequency of these cloud types in this region. In the shortwave radiation scheme (SRTM, Mlawer and Clough, 1997) the FouqartBonnel scheme is replaced by a scheme that is based on the correlated $k$ method (Lacis, 1991). The latter is shown to lead to an overall improved accuracy in calculated fluxes and heating rates (ECWMF-IFS, 2008).

The last relevant physics change is the newly implemented Eddy-Diffusivity Mass Flux (EDMF, Siebesma et al., 2007) scheme for boundary-layer turbulence/shallow convection. This scheme distinguishes between large-scale (updraughts) and small-scale (turbulence) mixing processes in the surface and boundary layer by describing them with either mass fluxes or diffusion. The surface flux relies on MoninObukhov similarity theory but takes into account form drag (Beljaars et al., 2004) that is dependent on subscale orography. For topographically rough areas like the Antarctic Peninsula these changes are expected to be especially important.

Furthermore, the RACMO2 model update incorporates changes in the HIRLAM dynamical core. These are mostly of numerical nature and are not addressed here. For a more detailed and complete description of the entire RACMO2 update the reader is referred to Van Meijgaard et al. (2012) and ECWMF-IFS (2008) and references therein. The changes in the cloud scheme influence precipitation patterns over Antarctica. Whether these changes represent an improvement, and how these changes effect the mass budget of the ice sheet will be addressed in a forthcoming study. The impact of precipitation changes on the SEB is small, as will be shown in Sect. 3.3. 


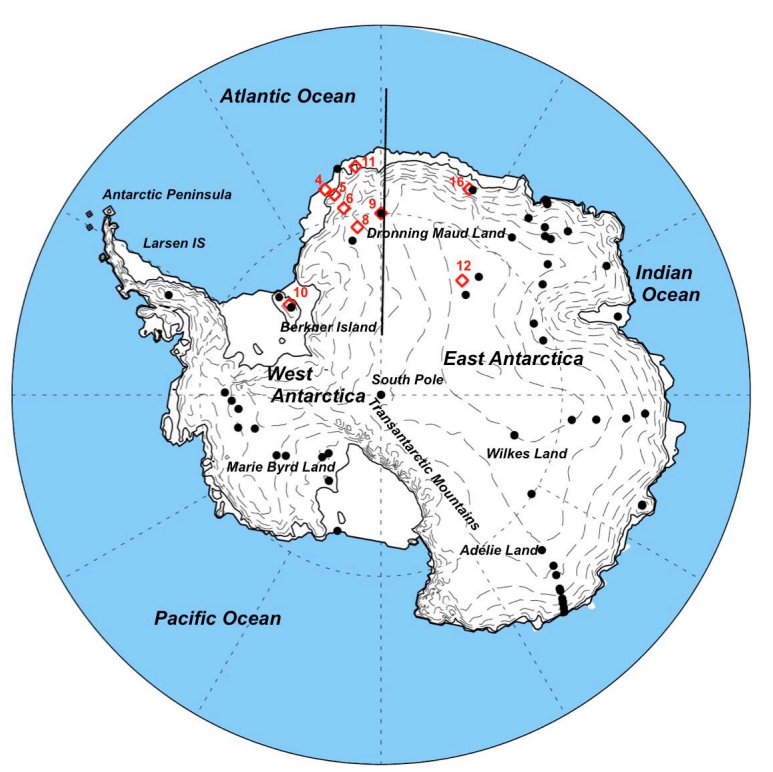

Fig. 1. Map of Antarctica with locations of the AWS (red diamonds) the 64 coring sites (black dots) and the position of the latitudinal cross-section used in Fig. 3. Also shown are the ice-shelf edge and grounding line (solid lines) and height intervals every $500 \mathrm{~m}$ (dashed lines) based on a digital elevation model from Liu et al. (2001).

\subsection{Observational data}

The near-surface wind, temperature and SEB are evaluated using observational data from nine automatic weather stations, maintained by the Institute for Marine and Atmospheric research of Utrecht University (UU/IMAU), see the IMAU AWS website http://www.projects.science.uu.nl/ iceclimate/aws. Importantly, these AWSs measure all four radiation components as well as humidity and snow temperature, and therefore enable a full closure of the SEB. All AWSs are of similar design: single level measurements of wind speed/direction, temperature and relative humidity are performed at a height of approximately $3 \mathrm{~m}$. The individual radiation components $(\mathrm{SW} \downarrow, \mathrm{SW} \uparrow, \mathrm{LW} \downarrow, \mathrm{LW} \uparrow)$ are measured with a single sensor. Treatment of the radiation fluxes follows Van den Broeke (2004). Figure 1 shows the locations of the AWSs. They are located in Dronning Maud Land (DML) in different climate regimes: from relatively mild and wet coastal sites (AWS 4 and 11) to the steep escarpment region of DML (AWS 5, 6 and 16), the south dome of Berkner Island (AWS 10) and the high and cold East Antarctic plateau (AWS 8, 9 and 12). Observation lengths range from 4 to $15 \mathrm{yr}$ of data. Due to instrumental problems and icing of the sensors some months of the data record are of lower quality. A summary of the location and data records of the AWSs is provided in Table 1. For more details see Van den Broeke et al. (2005a, b) and Reijmer and Oerlemans (2002).
The SEB can be written as

$M=\mathrm{SW}_{\text {net }}+\mathrm{LW}_{\text {net }}+\mathrm{SHF}+\mathrm{LHF}+G$,

where fluxes directed towards the surface are defined positive with units of $\mathrm{W} \mathrm{m}^{-2}, M$ is melt energy ( $M=0$ if the surface temperature $\left.T_{\mathrm{S}}<273.15 \mathrm{~K}\right), \mathrm{SW}_{\text {net }}$ and $\mathrm{LW}_{\text {net }}$ are the net shortwave and long-wave radiative fluxes, SHF and LHF are the sensible and latent heat fluxes and $G$ is the subsurface conductive heat flux. The sensible- and latent-turbulent heat fluxes are calculated using Monin-Obukhov similarity theory using the bulk method (Van den Broeke et al., 2005b). This implies that the turbulent fluxes and surface temperatures are calculated values and not direct measurements. All data from the nine AWSs are monthly averaged (resulting in 770 station-months) and compared with data from the same months of the two RACMO cycles. An assessment of the quality of the observational data can be found in Reijmer and Oerlemans (2002); Van den Broeke et al. (2004).

As the AWSs only cover a limited part of East Antarctica, 64 snow temperature observations (Fig. 1) are additionally used to evaluate the spatial performance of RACMO2 for $T_{\mathrm{s}}$. The $10 \mathrm{~m}$ snow temperature is assumed to represent the annual mean surface temperature, a reasonable assumption in areas without melt. Note that at a model resolution of $27 \mathrm{~km}$, the observational data are compared with data from the nearest model grid point. For the $10 \mathrm{~m}$ snow temperatures, this causes four locations to fall outside of the ice mask. For these points the nearest grid point that does fall within the ice mask is used.

\section{Results}

\subsection{General climate characteristics}

In Antarctica a negative to zero net radiation budget prevails during most months. In summer the radiation budget regularly becomes positive due to absorption of shortwave radiation at the surface. In winter, the radiation budget is balanced mainly by a positive (downward directed) SHF, as LHF is generally small due to the low humidity and thus small nearsurface moisture gradients exist over the Antarctic ice sheet. The negative radiation budget prevails and cools the surface, resulting in a quasi-permanent surface-based temperature inversion. In combination with a sloping surface, this leads to the characteristic persistent katabatic winds over the Antarctic ice sheet. As the cooling is stronger in winter, the katabatic winds increase in strength in winter. Stronger katabatic winds enhance downward sensible heat transport, which counteracts the strength of the surface temperature inversion by increasing the surface temperature. This results in a weaker seasonality of (near-)surface temperature in high wind speed areas.

To illustrate these interactive processes, Fig. 2 shows the monthly mean values of $10 \mathrm{~m}$ wind speed $\left(V_{10 \mathrm{~m}}\right)$, surface 
Table 1. The AWS topographic characteristics and period of operation (until December 2011). No. months represents the number of available months over total months (725/770) of the model period (January 1979-December 2011). If no end time is indicated, the AWS is still operational end of 2011. Observed surface slope $\left(\mathrm{m} \mathrm{km}^{-1}\right)$ is based on a $1 \mathrm{~km} \times 1 \mathrm{~km}$ digital elevation model (Liu et al., 2001), modelled surface slope is based on the $27 \mathrm{~km}$ interpolated grid.

\begin{tabular}{lrrrrrrrrr}
\hline AWS & 4 & 5 & 6 & 8 & 9 & 10 & 11 & 12 \\
\hline Latitude & $72^{\circ} 45^{\prime} \mathrm{S}$ & $73^{\circ} 06^{\prime} \mathrm{S}$ & $74^{\circ} 28^{\prime} \mathrm{S}$ & $76^{\circ} 00^{\prime} \mathrm{S}$ & $75^{\circ} 00^{\prime} \mathrm{S}$ & $79^{\circ} 34^{\prime} \mathrm{S}$ & $71^{\circ} 09^{\prime} \mathrm{S}$ & $78^{\circ} 39^{\prime} \mathrm{S}$ & $71^{\circ} 57^{\prime} \mathrm{S}$ \\
Longitude & $15^{\circ} 299^{\prime} \mathrm{W}$ & $13^{\circ} 09.9^{\prime} \mathrm{W}$ & $11^{\circ} 31.0^{\prime} \mathrm{W}$ & $08^{\circ} 03^{\prime} \mathrm{W}$ & $00^{\circ} 00^{\prime} \mathrm{E} / \mathrm{W}$ & $45^{\circ} 47^{\prime} \mathrm{W}$ & $06^{\circ} 42^{\prime} \mathrm{W}$ & $35^{\circ} 38^{\prime} \mathrm{E}$ & $23^{\circ} 20^{\prime} \mathrm{E}$ \\
Elevation (obs) & $34 \mathrm{~m}$ & $363 \mathrm{~m}$ & $1160 \mathrm{~m}$ & $2400 \mathrm{~m}$ & $2892 \mathrm{~m}$ & $890 \mathrm{~m}$ & $700 \mathrm{~m}$ & $3620 \mathrm{~m}$ & $1300 \mathrm{~m}$ \\
Elevation (mod) & $23 \mathrm{~m}$ & $332 \mathrm{~m}$ & $1219 \mathrm{~m}$ & $2405 \mathrm{~m}$ & $2856 \mathrm{~m}$ & $789 \mathrm{~m}$ & $224 \mathrm{~m}$ & $3621 \mathrm{~m}$ & $1130 \mathrm{~m}$ \\
Slope (obs) & 1.0 & 23.1 & 38.4 & 2.0 & 1.5 & 1.1 & 15.5 & 2.0 & 15.6 \\
Slope (mod) & 3.4 & 7.8 & 28.9 & 3.5 & 2.0 & 5.1 & 10.7 & 2.2 & 16.2 \\
Start & Dec 1997 & Feb 1998 & Jan 1998 & Jan 1998 & Dec 1997 & Jan 2001 & Jan 2007 & Dec 2007 & Feb 2009 \\
End & Dec 2002 & - & Jan 2009 & Jan 2003 & - & Jan 2006 & - & - & - \\
no. months & $60 / 60$ & $167 / 167$ & $134 / 134$ & $19 / 44$ & $162 / 168$ & $48 / 54$ & $57 / 59$ & $49 / 49$ & $29 / 35$ \\
\hline
\end{tabular}
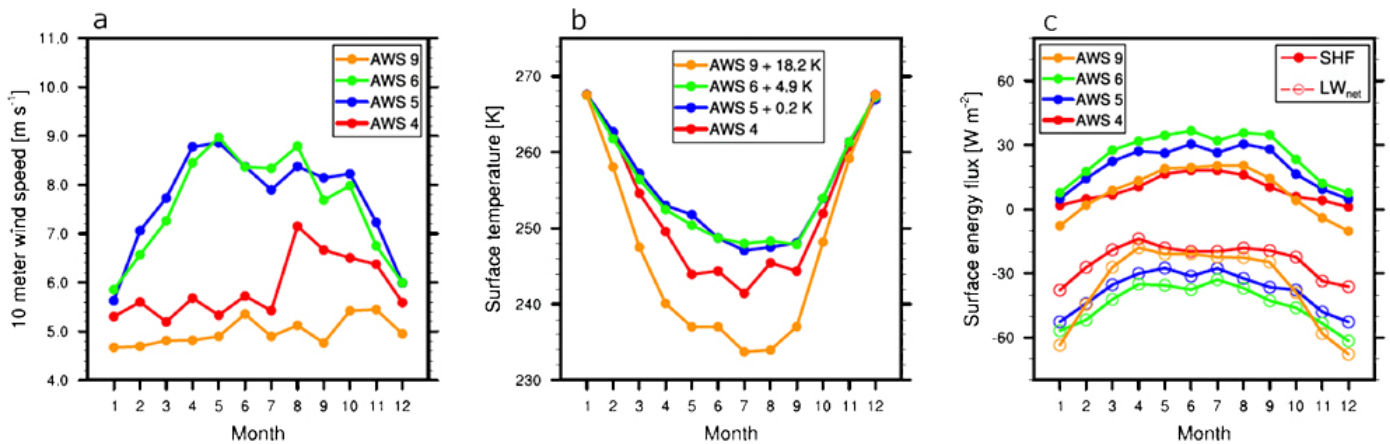

Fig. 2. Monthly mean (a) $10 \mathrm{~m}$ wind speed $\left(V_{10} \mathrm{~m}\right)$, (b) surface temperature $\left(T_{\mathrm{S}}\right)$ and (c) sensible heat flux (SHF) and net long-wave radiation (LW $\mathrm{LWt}_{\text {net }}$ for AWS 4, AWS 5, AWS 6 and AWS 9. The temperature curves for AWS 5, 6 and 9 (Fig. 2b) are shifted upward by 0.2, 4.9 and 18.2 K, respectively, to correct for elevation and continentality differences (Van den Broeke, 2004).

temperature $\left(T_{\mathrm{S}}\right)$, net long-wave radiation $\left(\mathrm{LW}_{\text {net }}\right)$ and sensible heat flux (SHF) for four AWSs in different climate zones of the Antarctic ice sheet (AWS 4, 5, 6 and 9). Figure 2a shows that monthly mean wind speeds for AWS 5 and 6 , in the steep escarpment region, exhibit a strong seasonal cycle due to stronger katabatic forcing in winter, with monthly mean wind speeds up to $9 \mathrm{~m} \mathrm{~s}^{-1}$. These katabatic winds mix warm air downward to the surface (large SHF), increasing surface temperature (Fig. 2b), and hence upward long-wave radiation (Fig. 2c). For AWS 4 and AWS 9, located on the relatively flat coastal ice shelf and interior ice sheet, respectively, wind speeds are lower and show no seasonal cycle. At these sites the seasonal amplitude in temperature is larger than at the sites dominated by katabatic winds (AWS 5 and 6) mainly because the wintertime surface temperature inversion is stronger.

\subsection{Changes in cloud properties and impact on simulated near-surface variables}

The new parameterisation for cloud ice super-saturation changes the total amount of modelled clouds over Antarctica, most notably over the East Antarctic plateau. To illustrate this effect, Fig. 3 shows a latitudinal cross-section of the ver- tical distribution of total cloud water/ice content, averaged over the period 1979-2011. A significant increase of modelled cloud content is found over the East Antarctic plateau, while cloud content has decreased along the coastline and over the ocean. With the new parameterisation, moist air that reaches the continent has to exceed $100 \%$ relative humidity by up to $50 \%$ in order to form clouds. As a result, clouds form farther inland and higher up in the troposphere, resulting in more clouds simulated by RACMO2.3 in the interior.

The increase in clouds has caused more downward longwave radiation to be emitted as seen in Fig. 4, where the difference fields (RACMO2.3-RACMO2.1) for LW $\downarrow$ (a), $T_{\mathrm{s}}$ (b), $V_{10 \mathrm{~m}}$ (c) and SHF (d) are shown. The increase in LW $\downarrow$ is found on most of the Antarctic ice sheet, but is strongest on the East Antarctic plateau, and has led to higher surface temperatures (Fig. 4b), reducing the temperature gradients in the surface layer and resulting in lower SHF values (Fig. 4d). A related pattern in near-surface wind speed is not seen (Fig. 4c), with changes being smaller than $5 \%$.

The increase in clouds over the continent also results in an increase of precipitation. This is illustrated in Fig. 5, which shows the changes in total precipitation (mostly snowfall) for DML, where the AWSs are located. The generally increased 

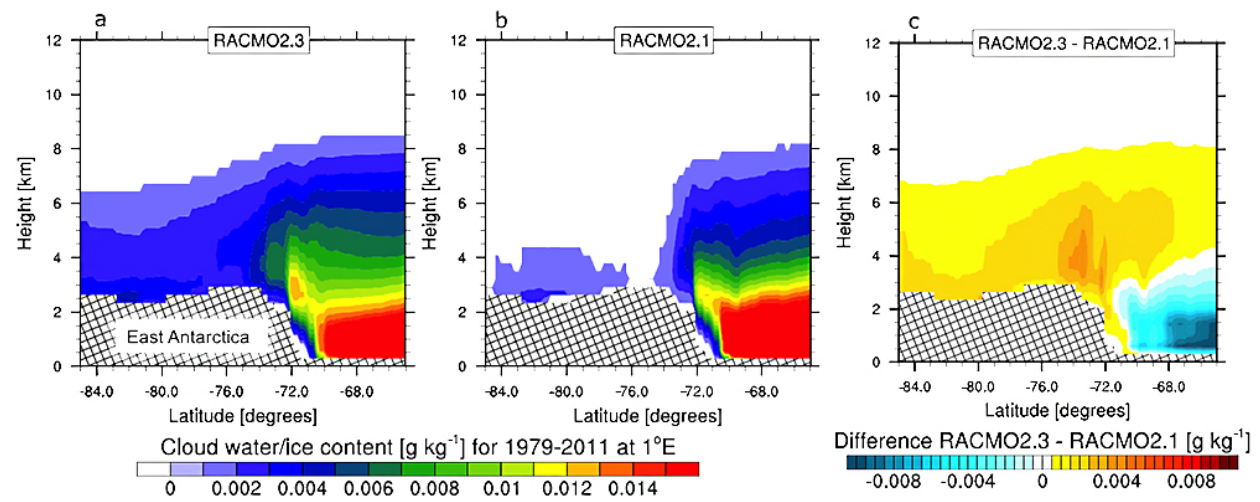

Fig. 3. Latitudinal cross-section of yearly (1979-2011) averaged total cloud water/ice content for (a) RACMO2.3, (b) RACMO2.1 and (c) the difference (RACMO2.3-RACMO2.1) at $1^{\circ}$ E. Location of cross-section is indicated in Fig. 1.
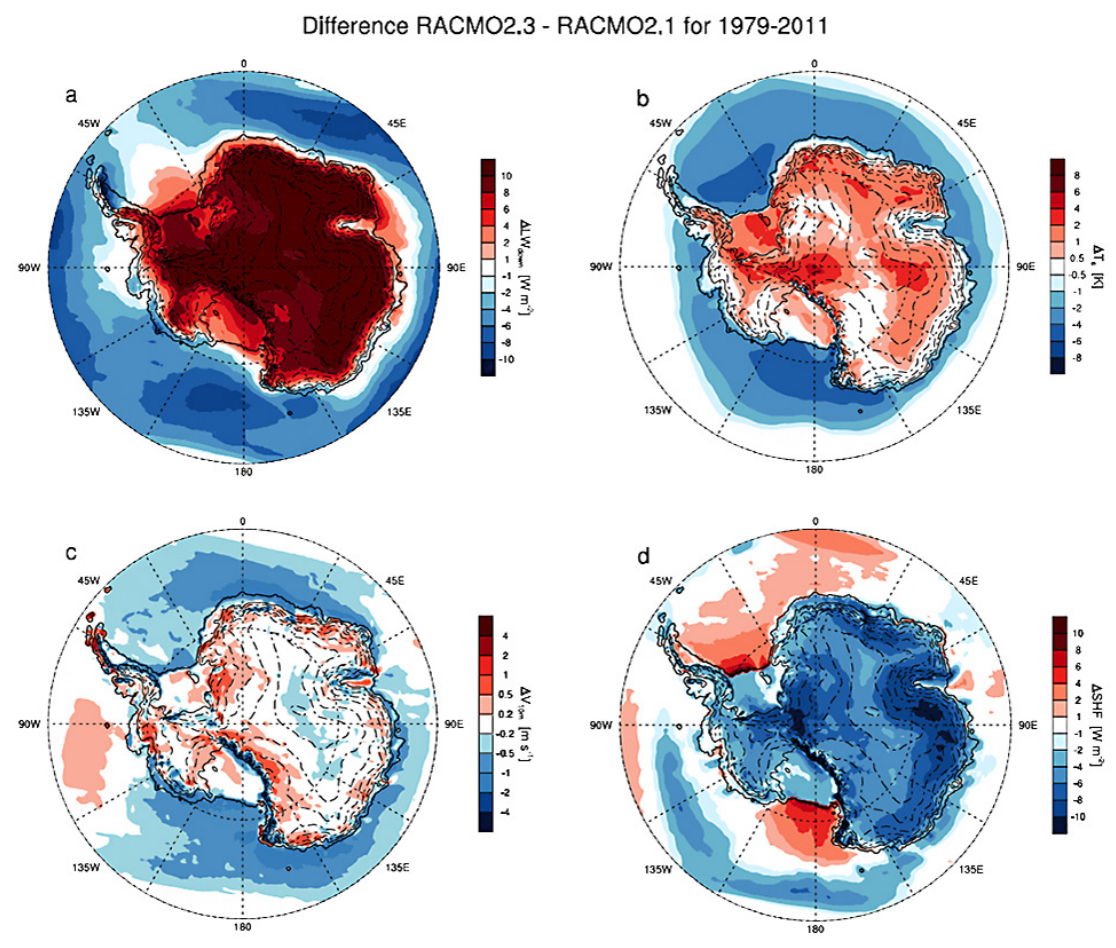

Fig. 4. Spatial distribution of difference (RACMO2.3-RACMO2.1) for $\mathrm{LW}_{\text {down }}(\mathbf{a}), T_{\mathrm{S}}(\mathbf{b}), V_{10 \mathrm{~m}}(\mathbf{c})$ and $\mathrm{SHF}(\mathbf{d})$.

precipitation will have an effect on the SEB through increased albedo (impacting the shortwave radiation) and sublimation (impacting latent heat flux). As will be shown in the next section, the effects on $\mathrm{SW}_{\text {net }}$ are small and limited to the short austral summer, while effects on LHF are generally small as well.

\subsection{Impact on simulation of the surface energy balance}

Figure 6 shows the difference between the monthly averaged modelled and observed SEB fluxes for all nine AWSs (>750 months) for RACMO2.3 and RACMO2.1. The aver- age bias and correlation coefficients are summarized in Table 2, as well as the bias standard deviation $\sigma_{\text {bias }}$ and root mean square deviation (RMSD). Most biases (and RMSD) are reduced in RACMO2.3: for SHF from $10.5 \mathrm{Wm}^{-2}$ to $7.1 \mathrm{Wm}^{-2}$, for $\mathrm{LW}_{\text {net }}$ from $-10.4 \mathrm{Wm}^{-2}$ to $-6.3 \mathrm{Wm}^{-2}$. The changes in LHF and $\mathrm{SW}_{\text {net }}$ are small. For $\mathrm{SW}_{\text {net }}$ the bias increased from $-1.3 \mathrm{Wm}^{-2}$ to $-2.0 \mathrm{Wm}^{-2}$ but the correlation remains high $\left(r^{2} \simeq 0.93\right)$. For LHF the slight improvement from $0.6 \mathrm{~W} \mathrm{~m}^{-2}$ to $0.4 \mathrm{~W} \mathrm{~m}^{-2}$ is of little significance due to its small magnitude and the uncertainty of the observed fluxes. The standard deviation $\sigma_{\text {bias }}$ has the same 


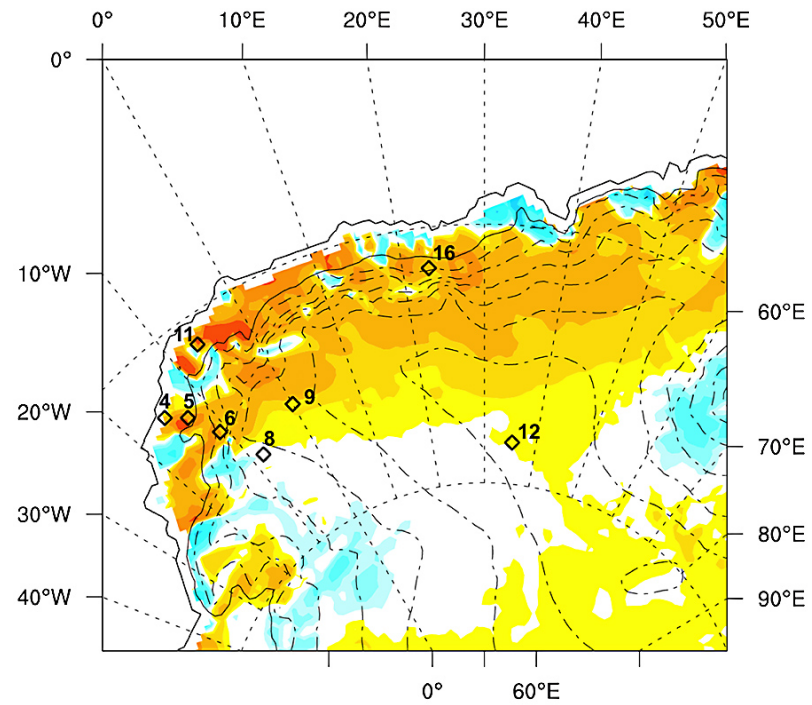

Fig. 5. Spatial distribution of difference (RACMO2.3-RACMO2.1) for total precipitation (rain + snowfall) in $\mathrm{mm}$ water equivalent per year over Dronning Maud Land, for 1979-2011. Shown are all the AWS, except AWS 10 that falls just outside of the boundary.
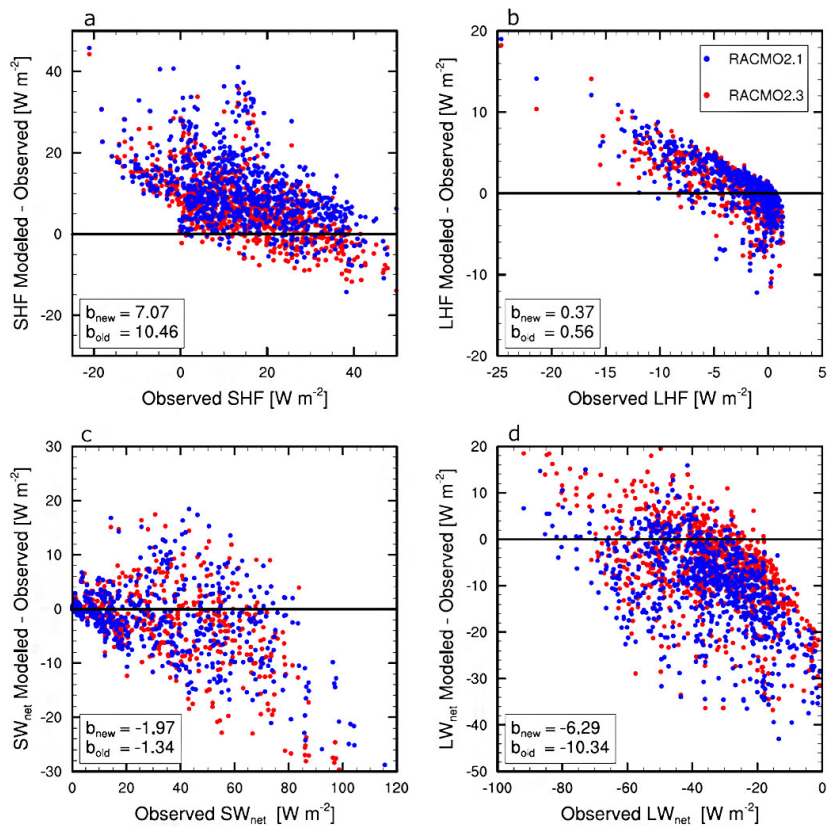

Fig. 6. Difference (modelled-observed of (a) sensible heat flux (SHF), (b) latent heat flux (LHF), (c) net shortwave radiation $\left(\mathrm{SW}_{\text {net }}\right)$ and $(\mathbf{d})$ net long-wave radiation $\left(\mathrm{LW}_{\text {net }}\right)$ as a function of the AWS observations. Shown are RACMO2.3 (red) with bias $b_{\text {new }}$ and RACMO2.1 (blue) with bias $b_{\text {old }}$. Biases (in $\left[\mathrm{W} \mathrm{m}^{-2}\right]$ ) are averages over all monthly average weather station data (>750 data points).

order of magnitude as the bias, suggesting that the improvements are not statistically significant because of the significant noise.
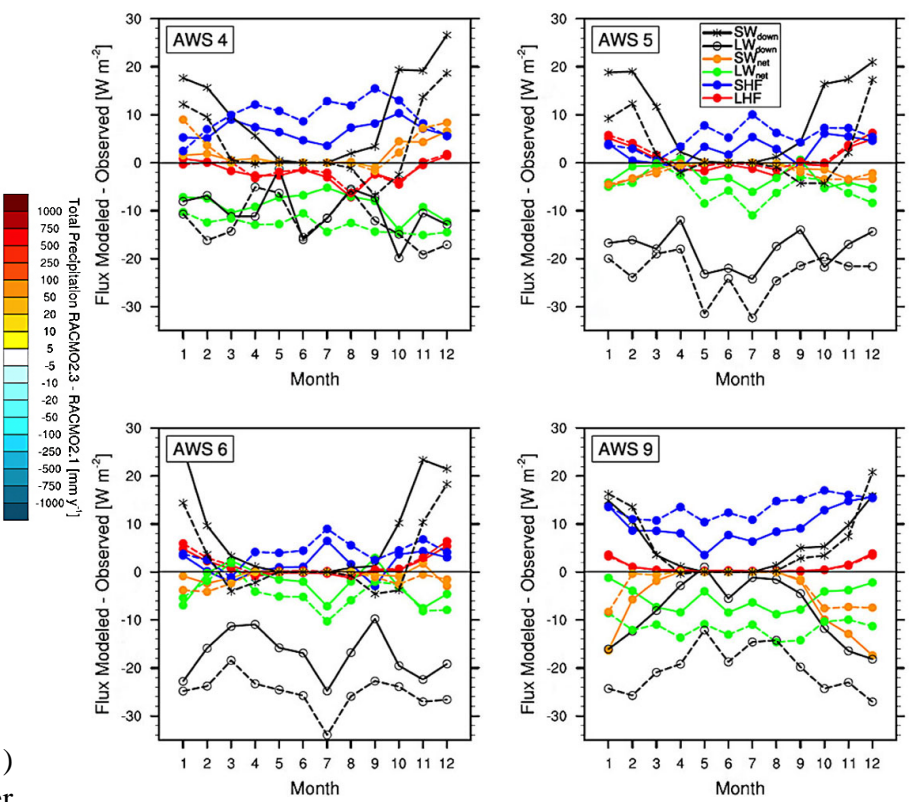

Fig. 7. Annual cycle of monthly mean difference (modelled-observed) of the SEB components (SHF (blue), $\mathrm{LHF}$ (red), $\mathrm{SW}_{\text {net }}$ (orange), $\mathrm{LW}_{\text {net }}$ (green)), LW $\downarrow$ (black circles) and SW $\downarrow$ (black asterisks) for (a) AWS 4, (b) AWS 5, (c) AWS 6 and (d) AWS 9. Shown are RACMO2.3 (solid line) and RACMO2.1 (dashed line).

To investigate the seasonal effects, Fig. 7 shows the monthly mean difference (modelled-observed) of SEB fluxes, $\mathrm{LW} \downarrow$ and $\mathrm{SW} \downarrow$ for AWS 4, 5, 6 and 9. $\mathrm{LW}_{\text {net }}$ is underestimated at the four AWS locations, and most significantly at AWS 4 and 9. The overestimated surface slope at these two sites is responsible for activating a katabatic feedback in winter, resulting in overestimated SHF. In RACMO2.3, the improved LW $\downarrow$ reduces this problem for the stations located more inland, as can be seen in Fig. 7, most significantly for AWS 9. For AWS 4 the improvement is not related to the increased LW $\downarrow$, but to a decreased LW $\uparrow$ (not shown). For this coastal site, $V_{10 \mathrm{~m}}$ that was overestimated has slightly decreased (the performance of the near-surface wind speed will be discussed in Sect. 3.4), resulting in a lower $T_{\mathrm{S}}$ and less long-wave cooling. For all AWS except AWS 9 the difference in SW $\downarrow$ has increased, most notably for the coastal AWSs. Here, changes in the radiation scheme have led to increased atmospheric transmissivity. For the more inland AWSs the effect of increased transmissivity is increasingly balanced by increased snowfall (see Fig. 5), raising the surface albedo and $\mathrm{SW} \uparrow$.

The underestimated surface slope results in too low wind speeds at AWS 5 and 6 , resulting in an overestimation of the surface temperature inversion (Fig. 9d). As a result, SHF is reasonably well represented, because stability effects remain small even at the underestimated wind speeds (Van den Broeke et al., 2005b). The problem is further reduced 
Table 2. Mean, bias (model-observation), standard deviation of the bias $\sigma$, root mean square deviation and correlation coefficient $\left(r^{2}\right.$ with significance level $p<0.0001$ ) for sensible heat flux (SHF), latent heat flux (LHF), net shortwave radiation ( $\mathrm{SW}_{\text {net }}$ ), net long-wave radiation $\left(\mathrm{LW}_{\text {net }}\right), 10 \mathrm{~m}$ wind speed $\left(V_{10 \mathrm{~m}}\right)$ and surface temperature $T_{\mathrm{S}}$ as modelled by RACMO2.1 and RACMO2.3 and as observed with the 9 AWSs (770 months). Also shown are the values for annual averaged $T_{\mathrm{S}}$ in comparison with $10 \mathrm{~m}$ snow temperatures from 64 ice-core measurements. For calculation of the statistics all 770 months are used.

\begin{tabular}{lcc|cccc|cccc}
\hline & & Obs & \multicolumn{5}{c|}{ RACMO2.1 } & \multicolumn{4}{c}{ RACMO2.3 } \\
\cline { 3 - 11 } & & mean & bias & $\sigma_{\text {bias }}$ & RMSD & $r^{2}$ & bias & $\sigma_{\text {bias }}$ & RMSD & $r^{2}$ \\
\hline SHF & {$\left[\mathrm{Wm}^{-2}\right]$} & 14.24 & 10.46 & 8.53 & 13.58 & 0.57 & 7.07 & 8.12 & 10.78 & 0.6 \\
$\mathrm{LHF}$ & {$\left[\mathrm{Wm}^{-2}\right]$} & -2.11 & 0.56 & 2.95 & 3.0 & 0.31 & 0.36 & 2.77 & 2.79 & 0.38 \\
$\mathrm{SW}_{\text {net }}$ & {$\left[\mathrm{Wm}^{-2}\right]$} & 22.73 & -1.33 & 6.23 & 6.41 & 0.94 & -1.96 & 7.60 & 7.86 & 0.92 \\
$\mathrm{LW}_{\text {net }}$ & {$\left[\mathrm{Wm}^{-2}\right]$} & -35.03 & -10.36 & 9.83 & 14.22 & 0.66 & -6.31 & 9.82 & 11.65 & 0.66 \\
$V_{10 \mathrm{~m}}$ & {$\left[\mathrm{~ms}^{-1}\right]$} & 6.38 & -0.48 & 1.67 & 1.74 & 0.28 & -0.51 & 1.64 & 1.72 & 0.27 \\
$T_{\mathrm{s}}$ (AWS) & {$[\mathrm{K}]$} & 244.28 & -3.24 & 4.5 & 5.57 & 0.91 & -1.91 & 4.36 & 4.77 & 0.91 \\
$T_{\mathrm{S}}$ (ice cores) & {$[\mathrm{K}]$} & 240.6 & -2.32 & 2.29 & 3.23 & 0.96 & -1.28 & 2.13 & 2.45 & 0.98 \\
\hline
\end{tabular}
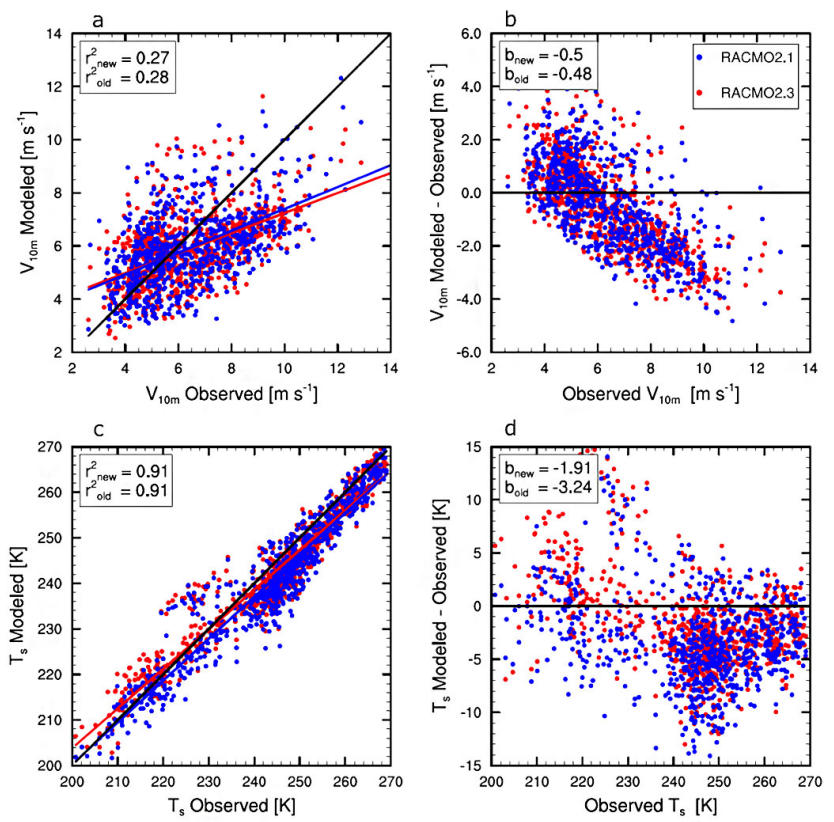

Fig. 8. Modelled and difference (modelled-observed) as a function of the AWS observations of $(\mathbf{a}, \mathbf{b})$ monthly averaged $10 \mathrm{~m}$ wind speed $\left(V_{10 \mathrm{~m}}\right)$ and $(\mathbf{c}, \mathbf{d})$ surface temperature $\left(T_{\mathrm{S}}\right)$. Shown are RACMO2.3 (red) with correlation $r_{\text {new }}^{2}$ and bias $b_{\text {new }}$ and RACMO2.1 (blue) with correlation $r_{\text {old }}^{2}$ and bias $b_{\text {old }}$. Biases are averages over all data with units [ $\mathrm{m} \mathrm{s}^{-1}$ ] for $V_{10 \mathrm{~m}}$ and [K] for $T_{\mathrm{S}}$.

in RACMO2.3, in which the SEB at AWS 5 and 6 is well represented.

In summer the SHF bias at AWS 4 is smaller because $\mathrm{SW}_{\text {net }}$ and LHF help to balance the excess long-wave cooling. For AWS 9, however, there is an increased negative bias in $\mathrm{SW}_{\text {net }}$ in RACMO2.3 due to an overestimated albedo (Van de Berg et al., 2007). To conclude, for most of the climate zones of the Antarctic ice sheet the improved representation of SEB components mainly results from a better represen-
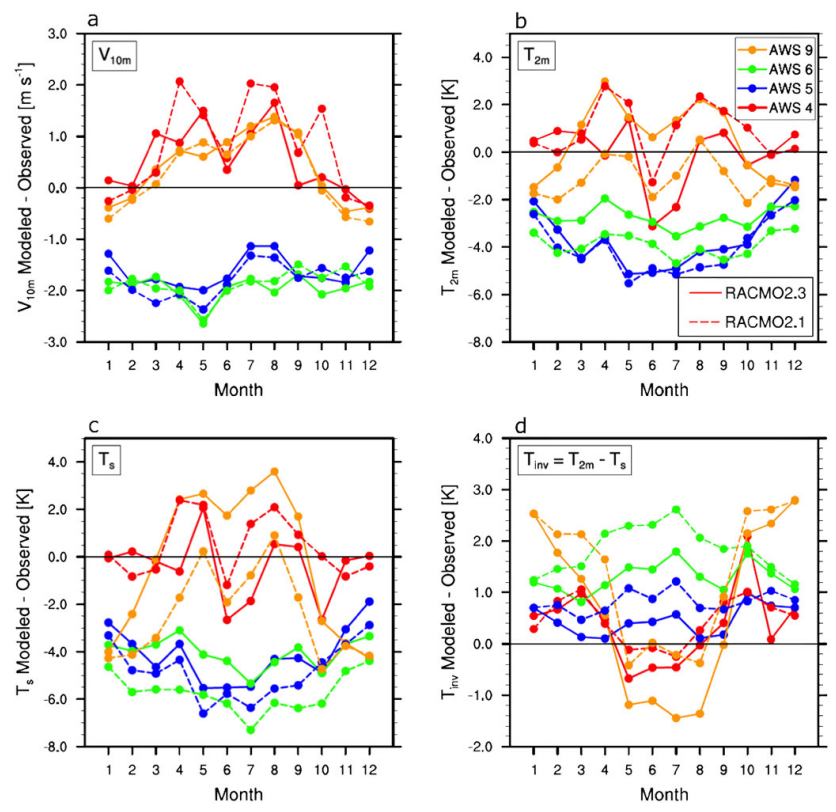

Fig. 9. Annual cycle of monthly mean difference (modelled-observed) of (a) $10 \mathrm{~m}$ wind speed $\left(V_{10 \mathrm{~m}}\right)$, (b) $2 \mathrm{~m}$ temperature $\left(T_{2} \mathrm{~m}\right),(\mathbf{c})$ surface temperature $\left(T_{\mathrm{S}}\right)$ and $(\mathbf{d})$ the surface temperature inversion $\left(T_{\mathrm{inv}}=T_{2 \mathrm{~m}}-T_{\mathrm{S}}\right)$ for AWS 4, AWS 5, AWS 6 and AWS 9. Shown are RACMO2.3 (solid line) and RACMO2.1 (dashed line).

tation of LW $\downarrow$, but also changes in the turbulence scheme (Sect. 3.5) contribute to the improvement.

Figure 6a confirms that high wintertime SHF values in the escarpment zone are well represented, and that RACMO2 generally overestimates SHF in flatter areas. This leads to overestimated $T_{\mathrm{S}}$ and hence too negative $\mathrm{LW}_{\text {net }}$ (Fig. 6d). Both biases are significantly reduced in RACMO2.3, by $33 \%$ (SHF) and $39 \%\left(\mathrm{LW}_{\text {net }}\right)$. In summer, RACMO2 underestimates $\mathrm{SW}_{\text {net }}$ in the high interior (Figs. $6 \mathrm{c}$ and $7 \mathrm{~d}$ ). As 
a result of the underestimation of $\mathrm{SW}_{\text {net }}, T_{\mathrm{S}}$ is underestimated (Figs. 8c, $\mathrm{d}$ and 9c), while the surface temperature inversion and the SHF are overestimated (Figs. 6a, 7d). As a result of too low $T_{\mathrm{s}}$, sublimation (negative LHF) is underestimated and summertime convection (upward SHF) is not modelled on the ice sheet (see Sect. 3.5).

\subsection{Impact on simulation of temperature and near-surface wind speed}

Figure 8 shows modelled values (Fig. 8a, c) and difference (model-observation) (Fig. 8b, d) of the monthly averaged wind speed and surface temperature of all AWSs as a function of the observed value. The figure also shows correlation coefficient $\left(r^{2}\right)$ and average bias (b), also denoted in Table 2. Figure $8 \mathrm{a}, \mathrm{b}$ shows that the wind speed representation has not improved in RACMO2.3 when compared to RACMO2.1 (for both data sets: $b \simeq 0.5, r^{2} \simeq 0.27$ ). Both model cycles generally underestimate high wind speeds and overestimate low wind speeds. Since near-surface winds over the Antarctic ice sheet are dominated by katabatic forcing, this is caused by an overestimation of surface slopes in relatively flat areas (AWS 4, 8, 9, 10,12) and an underestimation of surface slopes in steep areas (AWS 5, 6, 11) in the escarpment region of DML (and elsewhere in Antarctica), as a result of the limited horizontal resolution of the model (Reijmer et al., 2005; Lenaerts et al., 2012b). The small differences in $V_{10 \mathrm{~m}}$ are due to the combined effect of model changes but the errors in wind speed with respect to the observations are dominated by the smoothed model topography (note that the model topography is the same in both model cycles).

Figure 9a shows the monthly mean difference (modelobservation) of $V_{10 \mathrm{~m}}$ for AWS 4, 5, 6 and 9. For AWS 5 and AWS 6 (slope $>10 \mathrm{~m} \mathrm{~km}^{-1}$ ) wind speed is underestimated year round. For AWS 4 and AWS 9 the wind speed is overestimated in winter, when katabatic forcing is overestimated, and therefore shows a seasonality that is too pronounced. This has a strong effect on surface and $2 \mathrm{~m}$ temperature, as shown in Fig. 9b, c, where temperature is underestimated at AWS 5 and 6. The surface temperature inversion, defined here as $T_{\mathrm{inv}}=T_{2 \mathrm{~m}}-T_{\mathrm{s}}$, is underestimated when wind speed is overestimated (AWS 4 and 9) (Fig. 9d), which is intuitively expected.

In contrast to wind speed, a clear improvement in surface temperature $T_{\mathrm{S}}$ (Fig. 8c, d) in RACMO2.3 over RACMO2.1 is seen, due to the increased LW $\downarrow$. The cold bias has been reduced from $3.2 \mathrm{~K}$ to $1.9 \mathrm{~K}$ while the correlation has not changed $\left(r^{2}=0.91\right)$. This improvement occurs year round for all the AWSs except for the coastal AWSs (see AWS 4), where the representation was already good due in part to the overestimated wind speed. A comparison of monthly averaged $V_{10 \mathrm{~m}}$ and $T_{2 \mathrm{~m}}$ from the Reference Antarctic Data for Environmental Research (READER, Turner et al., 2004) AWS and surface station data gave the same results (not shown).

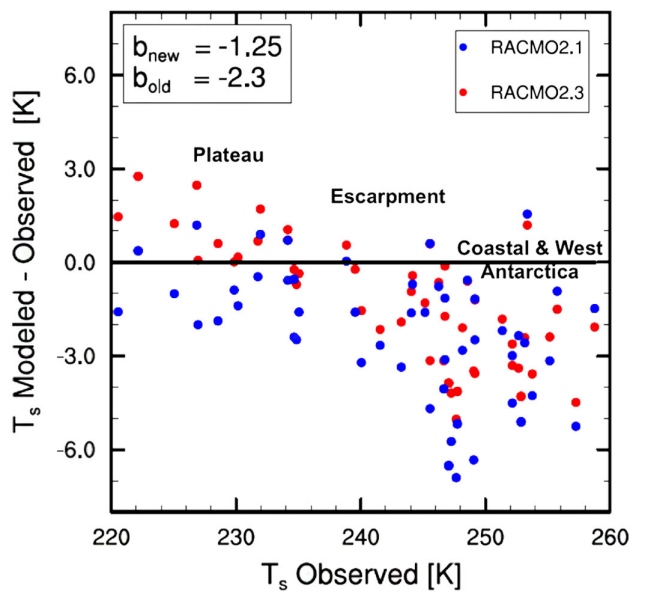

Fig. 10. Difference (modelled-observed) of the annual period averaged (1979-2011) surface temperature $\left(T_{\mathrm{S}}\right)$ as a function of $10 \mathrm{~m}$ ice-core observations. Shown are RACMO2.3 (red) with bias $b_{\text {new }}$ and RACMO2.1 (blue) with bias $b_{\text {old }}$ (in $[\mathrm{K}]$ ).

Since the AWS are located mainly in DML, which has a topography that is not typical for the entire ice sheet, we use $10 \mathrm{~m}$-snow temperature data to obtain a better spatial coverage for the $T_{\mathrm{s}}$ evaluation (Fig. 1). Figure 10 shows the difference between modelled and observed $T_{\mathrm{S}}$ as a function of the latter, averaged over the model time span. Average values, bias, $\sigma_{\text {bias }}$, RMSD and correlation are given in Table 2. Surface temperatures in RACMO2.1 are underestimated at almost all locations and on average are too low by $2.3 \mathrm{~K}$. RACMO2.3 reduces this bias to $-1.3 \mathrm{~K}$. Overall the spatial variability of surface temperatures is well represented by both model versions $\left(r^{2}=0.96\right.$ for RACMO2.1 and $r^{2}=0.98$ for RACMO2.3) although there seems to be a tendency towards larger underestimations at higher temperature locations. Figure 10 shows that the best agreement is found on the cold East Antarctic plateau, where the overestimated wind speeds compensate for the bias in temperature caused by the underestimated LW $\downarrow$. Because of the improved $\mathrm{LW} \downarrow, T_{\mathrm{s}}$ on the plateau has changed from being slightly underestimated in RACMO2.1 to being slightly overestimated in RACMO2.3. In coastal and West Antarctica, $T_{\mathrm{S}}$ is underestimated the most, due to both $V_{10 \mathrm{~m}}$ and $\mathrm{LW}_{\text {net }}$ being underestimated, and it is here that RACMO2.3 produces the largest improvement.

\subsection{Impact on SHF regimes}

To assess the impact of changes in the atmospheric surface layer scheme, Fig. 11 shows monthly averaged SHF for all AWSs (a), RACMO2.3 (b) and RACMO2.1 (c) as a function of the surface temperature inversion and wind speed (colour scheme). The filled circles represent winter conditions (April-September), open circles conditions for October-March. Figure 11a clearly shows four regimes. 

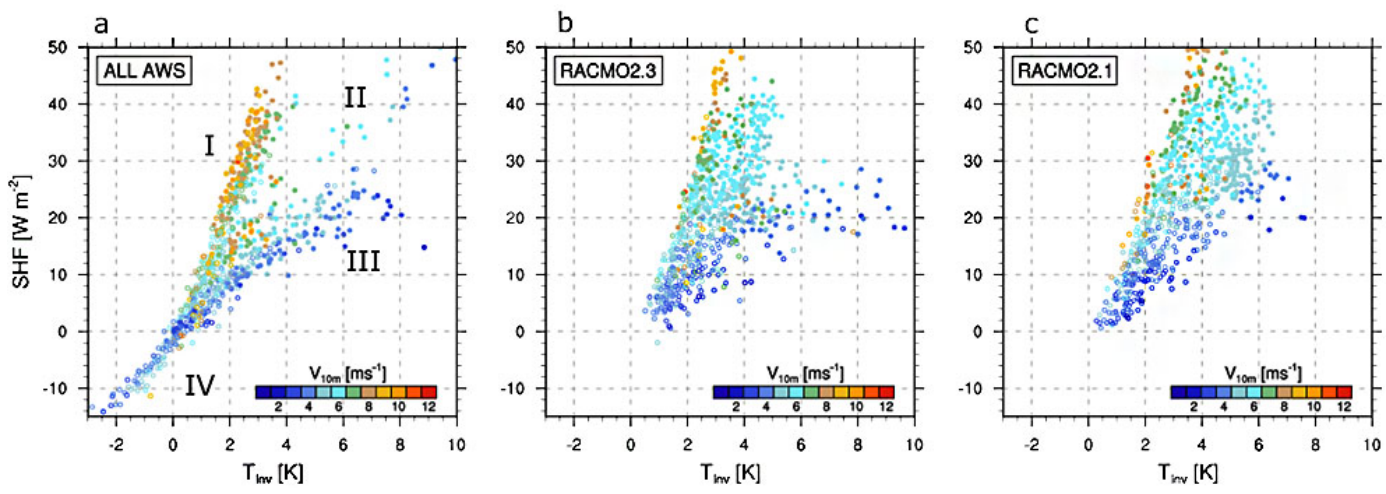

Fig. 11. Monthly averaged SHF as a function of the surface temperature inversion $\left(T_{\mathrm{inv}}=T_{2 \mathrm{~m}}-T_{\mathrm{S}}\right.$ ) for (a) all AWSs, (b) RACMO2.3 and (c) RACMO2.1. The colour scheme represents wind speed $V_{10 \mathrm{~m}}$ and model data is from the same months and locations as the observational data. Filled circles are winter values (months 4-9) and open circles represent months (10-3). Four climate regimes are denoted, and explained in Sect. 3.5.

Regime I represents the katabatic wind zone where SHF increases quadratically with the katabatic wind forcing (inversion strength). Regime II represents the exceptional conditions at AWS 16 (Thiery et al., 2012; Gorodetskaya et al., 2013), where despite stable conditions and low wind speeds, SHF values are high probably due to large-scale circulation effects. The model (Fig. 11b, c) does not simulate this regime accurately due to the limited spatial resolution as the station is positioned in a topographically complex region. Regime III represents the stable conditions of the AWSs in flat areas where static stability effects become important at high values of the temperature inversion, suppressing SHF.

For lower stabilities and towards summer conditions the branches join and SHF shows a linear dependence on $T_{\mathrm{inv}}$, the negative values indicating the convective summertime conditions at plateau stations AWS 9 and 12 (Regime IV). This regime is exclusively found on the plateau, where the low summertime temperatures prevent sublimation (LHF) to act as a surface energy sink (King et al., 2006). Because RACMO2 overestimates albedo and underestimates atmospheric transmissivity, a positive radiation balance is not simulated and convection does not occur (at least not in the monthly mean sense).

Figure $11 \mathrm{~b}, \mathrm{c}$ shows the inability of RACMO2 to simulate regimes II and IV. The behaviour in the katabatic wind zone is represented well, although the branch is less pronounced due to the underestimation of the slope and hence wind speeds. RACMO2.3 simulates an improved separation of the most important regimes II and III compared to RACMO2.1, because of the improved surface layer turbulence scheme and general changes in the simulated results.

\section{Conclusions}

The physics package of the regional atmospheric climate model RACMO2 adopted from the ECMWF-IFS has been upgraded from cycle CY23r4 (RACMO2.1) to CY33r1 (RACMO2.3). This study evaluates the effects of this change on the Antarctic surface energy balance (SEB), $10 \mathrm{~m}$ wind speed $V_{10 \mathrm{~m}}$ and surface temperature $T_{\mathrm{s}}$ by comparing both cycles with observational SEB data gathered from nine automatic weather stations in East Antarctica and 64 deep snow temperature sites. The model has improved in several aspects. Due to the inclusion of a parameterization for cloud ice super-saturation, more clouds and increased moisture content are simulated in the upper troposphere. As a result, more clouds and an increased cloud optical thickness in the interior have resulted in more downward longwave radiation. Consequently, in RACMO2.3 the biases in the sensible heat flux (SHF) and the net long-wave radiation $\left(\mathrm{LW}_{\text {net }}\right)$ have decreased from 10.5 to $7.1 \mathrm{~W} \mathrm{~m}^{-2}$ and -10.4 to $-6.3 \mathrm{~W} \mathrm{~m}^{-2}$, respectively. The change in long-wave radiation has improved the bias in the SHF through its tight coupling with $T_{\mathrm{S}}$ and wind speed: the bias in $T_{\mathrm{S}}$, based on the deep snow temperature observations, has decreased from $-2.3 \mathrm{~K}$ to $-1.3 \mathrm{~K}$. Near-surface air temperatures have also increased but less so than $T_{\mathrm{s}}$, decreasing the surface-based temperature inversion. The bias in $V_{10 \mathrm{~m}}$, which is mainly due to the flattened ice sheet topography at the limited model resolution, remains unchanged.

Acknowledgements. We are grateful for the financial support of NWO/ALW, Netherlands Polar Programme. The installation and maintenance of AWS 16 was financed by the Belgian Science Policy Office under grant number EN/01/4B supervised by N. van Lipzig KU Leuven. We thank I. Gorodetskaya for providing AWS 16 data.

Edited by: E. Hanna 


\section{References}

Barker, H. W., Cole, J. N. S., Morcrette, J., and Pincus, R.: The Monte Carlo Independent Column Approximation : An assessment using several global atmospheric models, Q. J. Roy. Meteor. Soc., 134, 1463-1478, doi:10.1002/qj.303, 2008.

Beljaars, A. C., Brown, A. R., and Wood, N.: A new parametrization of turbulent orographic form drag, Q. J. Roy. Meteor. Soc., 130, 1327-1347, doi:10.1256/qj.03.73, 2004.

Carroll, J. J.: Long-Term Means and Short-term Variablity of the Surface Energy Balance Components at the South Pole, J. Geophys. Res., 87, 4277-4286, 1982.

Chen, J. L., Wilson, C. R., Blankenship, D. D., and Tapley, B. D.: Antarctic mass rates from GRACE, Geophys. Res. Lett., 33, L11502, doi:10.1029/2006GL026369, 2006.

Dee, D. P., Uppala, S. M., Simmons, A. J., Berrisford, P., Poli, P., Kobayashi, S., Andrae, U., Balmaseda, M. A., Balsamo, G., Bauer, P., Bechtold, P., Beljaars, A. C. M., Van de Berg, L., Bidlot, J., Bormann, N., Delsol, C., Dragani, R., Fuentes, M., Geer, A. J., Haimberger, L., Healy, S. B., Hersbach, H., Hólm, E. V., Isaksen, L., Kå llberg, P., Köhler, M., Matricardi, M., McNally, A. P., Monge-Sanz, B. M., Morcrette, J. J., Park, B. K., Peubey, C., de Rosnay, P., Tavolato, C., Thépaut, J. N., and Vitart, F.: The ERA-Interim reanalysis: configuration and performance of the data assimilation system, Q. J. Roy. Meteor. Soc., 137, 553-597, doi:10.1002/qj.828, 2011.

ECWMF-IFS: Part IV : Physical Processes (CY33R1), Tech. Rep. June, http://www.ecmwf.int/research/ifsdocs/CY33r1/ PHYSICS/IFSPart4.pdf (last access: 29 October 2012), 2008.

Ettema, J., van den Broeke, M. R., van Meijgaard, E., and van de Berg, W. J.: Climate of the Greenland ice sheet using a highresolution climate model - Part 2: Near-surface climate and energy balance, The Cryosphere, 4, 529-544, doi:10.5194/tc-4529-2010, 2010a.

Ettema, J., van den Broeke, M. R., van Meijgaard, E., van de Berg, W. J., Box, J. E., and Steffen, K.: Climate of the Greenland ice sheet using a high-resolution climate model - Part 1: Evaluation, The Cryosphere, 4, 511-527, doi:10.5194/tc-4-511-2010, $2010 \mathrm{~b}$.

Fettweis, X.: Reconstruction of the 1979-2006 Greenland ice sheet surface mass balance using the regional climate model MAR, The Cryosphere, 1, 21-40, doi:10.5194/tc-1-21-2007, 2007.

Gorodetskaya, I. V., Van Lipzig, N. P. M., Van den Broeke, M. R., Mangold, A., Boot, W., and Reijmer, C. H.: Meteorological regimes and accumulation patterns at Utsteinen, Dronning Maud Land, East Antarctica: Analysis of two contrasting years, J. Geophys. Res., 118, 1700-1715, doi:10.1002/jgrd.50177, 2013.

Greuell, W. and Konzelmann, T.: Numerical modelling of the energy balance and the englacial temperature of the Greenland Ice Sheet. Calculations for the ETH-Camp location (West Greenland, 1155 ma.s.l.), Global Planet. Change, 9, 91-114, doi:10.1016/0921-8181(94)90010-8, 1994.

King, J. C., Argentini, S. A., and Anderson, P. S.: Contrasts between the summertime surface energy balance and boundary layer structure at Dome C and Halley stations, Antarctica, J. Geophys. Res., 111, D02105, doi:10.1029/2005JD006130, 2006.

Kuipers Munneke, P., Van den Broeke, M. R., Lenaerts, J. T. M., Flanner, M. G., Gardner, A. S., and Van de Berg, W. J.: A new albedo parameterization for use in climate models over the Antarctic ice sheet, J. Geophys. Res., 116, D05114, doi:10.1029/2010JD015113, 2011.
Lacis, A.: A Description of the Correlated k Distribution Method for Modeling Nongray Gaseous Absorption, Thermal Emission, and Multiple Scattering in Vertically Inhomogeneous Atmospheres to N2 ). Comparison cooling, J. Geophys. Res., 96, 9027-9063, 1991.

Lenaerts, J. T. M., Van den Broeke, M. R., Déry, S. J., Van Meijgaard, E., Van de Berg, W. J., Palm, S. P., and Sanz Rodrigo, J.: Modeling drifting snow in Antarctica with a regional climate model: 1. Methods and model evaluation, J. Geophys. Res., 117, D05108, doi:10.1029/2011JD016145, 2012a.

Lenaerts, J. T. M., Van Den Broeke, M. R., Scarchilli, C., and Agosta, C.: Impact of model resolution on simulated wind, drifting snow and surface mass balance in Terre Adélie, East Antarctica, J. Glaciol., 58, 821-829, doi:10.3189/2012JoG12J020, $2012 b$.

Ligtenberg, S. R. M., Horwath, M., Van den Broeke, M. R., and Legrésy, B.: Quantifying the seasonal breathing of the Antarctic ice sheet, Geophys. Res. Lett., 39, L23501, doi:10.1029/2012GL053628, 2012.

Liu, H., Jezek, K., Li, B., and Zhao, Z.: Radarsat Antarctic Mapping Project Digital Elevation Model Version 2., Tech. rep., 2001.

Mlawer, E. J. and Clough, S. A.: Shortwave and Longwave Enhancements in the Rapid Radiative Transfer Model, in: Proc. 7th Atmospheric Radiation Measurement (ARM) Science Team Meeting, 1992, 409-413, 1997.

Morcrette, J.-J., Barker, H. W., Cole, J. N. S., Iacono, M. J., and Pincus, R.: Impact of a New Radiation Package, McRad, in the ECMWF Integrated Forecasting System, Mon. Weather Rev., 136, 4773-4798, doi:10.1175/2008MWR2363.1, 2008.

Reijmer, C. H. and Oerlemans, J.: Temporal and spatial variability of the surface energy balance in Dronning Maud Land, East Antarctica, J. Geophys. Res., 107, 4759, doi:10.1029/2000JD000110, 2002.

Reijmer, C. H., Van Meijgaard, E., and Van den Broeke, M. R.: Evaluation of temperature and wind over Antarctica in a Regional Atmospheric Climate Model using 1 year of automatic weather station data and upper air observations, J. Geophys. Res., 110, D04103, doi:10.1029/2004JD005234, 2005.

Rignot, E., Bamber, J. L., Van den Broeke, M. R., Davis, C., Li, Y., Van de Berg, W. J., and Van Meijgaard, E.: Recent Antarctic ice mass loss from radar interferometry and regional climate modelling, Nat. Geosci., 1, 106-110, doi:10.1038/ngeo102, 2008.

Schlatter, T. W.: The Local Surface Energy Balance and Subsurface Temperature Regime in Antarctica, J. Appl. Meteorol., 11, 10481062, 1970.

Siebesma, A. P., Soares, P. M. M., and Teixeira, J.: A Combined Eddy-Diffusivity Mass-Flux Approach for the Convective Boundary Layer, J. Atmos. Sci., 64, 1230-1248, doi:10.1175/JAS3888.1, 2007.

Spichtinger, P., Gierens, K., and Read, W.: The global distribution of ice-supersaturated regions as seen by the Microwave Limb Sounder, Q. J. Roy. Meteor. Soc., 129, 3391-3410, doi:10.1256/qj.02.141, 2003.

Thiery, W., Gorodetskaya, I. V., Bintanja, R., Van Lipzig, N. P. M., Van den Broeke, M. R., Reijmer, C. H., and Kuipers Munneke, P.: Surface and snowdrift sublimation at Princess Elisabeth station, East Antarctica, The Cryosphere, 6, 841-857, doi:10.5194/tc-6841-2012, 2012. 
Tompkins, A. M. and Gierens, K.: Ice supersaturation in the ECMWF integrated forecast, Q. J. Roy. Meteor. Soc., 133, 5363, doi:10.1002/qj.14, 2007.

Turner, J., Colwell, S. R., Marshall, G. J., Lachlan-Cope, T. A., Carleton, A. M., Jones, P. D., and Reid, P. A.: The SCAR READER Project : Toward a High-Quality Database of Mean Antarctic Meteorological Observations, J. Climate, 17, 2890-2898, 2004.

Undén, P., Rontu, L., Jarvinen, H., Lynch, P., Calvo, J., Cats, G., Cuxart, J., Eerola, K., Fortelius, C., Garcia-moya, J. A., Jones, C., Lenderlink, G., Mcdonald, A., Mcgrath, R., and Navascues, B.: HIRLAM-5 Scientific Documentation, Tech. Rep. December, Swedish Meteorology and Hydrology Institute, 2002.

Van de Berg, W. J., Van den Broeke, M. R., Reijmer, C. H., and Van Meijgaard, E.: Characteristics of the Antarctic surface mass balance, 1958-2002, using a regional atmospheric climate model, Ann. Glaciol., 41, 97-104, doi:10.3189/172756405781813302, 2005.

Van de Berg, W. J., Van den Broeke, M. R., and Van Meijgaard, E.: Heat budget of the East Antarctic lower atmosphere derived from a regional atmospheric climate model, J. Geophys. Res., 112, D23101, doi:10.1029/2007JD008613, 2007.

Van den Broeke, M. R.: Surface radiation balance in Antarctica as measured with automatic weather stations, J. Geophys. Res., 109, D04103, doi:10.1029/2003JD004394, 2004.

Van den Broeke, M. R.: Depth and density of the Antarctic firn layer, Arct. Antarct. Alp. Res., 40, 432-438, doi:10.1657/15230430(07-021)[BROEKE]2.0.CO;2, 2008.
Van den Broeke, M. R., Van As, D., Reijmer, C. H., and Van de Wal, R. S. W.: Assessing and Improving the Quality of Unattended Radiation Observations in Antarctica, J. Atmos. Ocean. Tech., 21, 1417-1431, doi:10.1175/15200426(2004)021<1417:AAITQO>2.0.CO;2, 2004.

Van den Broeke, M. R., Reijmer, C. H., and Van As, D.: Seasonal cycles of Antarctic surface energy balance from automatic weather stations, Ann. Glaciol., 41, 131-139, $2005 \mathrm{a}$.

Van den Broeke, M. R., Van As, D., Reijmer, C. H., and Van de Wal, R. S. W.: Sensible heat exchange at the Antarctic snow surface: a study with automatic weather stations, Int. J. Climatol., 25, 1081-1101, doi:10.1002/joc.1152, 2005b.

Van Lipzig, N. P. M., Van Meijgaard, E., and Oerlemans, J.: Evaluation of a Regional Atmospheric Model Using Measurements of Surface Heat Exchange Processes from a Site in Antarctica, Mon. Weather Rev., 127, 1994-2011, 1999.

Van Lipzig, N. P. M., Van Meijgaard, E., and Oerlemans, J.: The spatial and temporal variability of the surface mass balance in Antarctica: results from a regional atmospheric climate model, Int. J. Climatol., 22, 1197-1217, doi:10.1002/joc.798, 2002.

Van Meijgaard, E., Van Ulft, L. H., Lenderink, G., De Roode, S. R., Wipfler, L., Boers, R., and Timmermans, A.: Refinement and application of a regional atmospheric model for climate scenario calculations of Western Europe, Climate changes Spatial Planning publication: KvR 054/12, 2012.

White, P. W.: Part IV : PHYSICAL PROCESSES (CY23R4 ), Tech. Rep. September, 2001. 